\title{
Experimental Analysis of the Line Side Behaviour of an Uncontrolled 12- Pulse Rectifier with Capacitive DC- Smoothing Compared to Analytical Analysis
}

\author{
Thomas Rechberger ${ }^{1}$ \\ ${ }^{1}$ Institute of Electrical Machines and Drives \\ Graz Unversity of Technology \\ Kopernikusgasse 24, A-8010 Graz, Austria \\ phone:+43 (0)316 873-7747, fax:+43 (0)316 873-7244, e-mail: Rechberger@ema.tugraz.at
}

\begin{abstract}
The analytical calculation of the line side behaviour of a 12-pulse diode rectifier with capacitive DCsmoothing is not described in any book, because the classical theory deals with the ideal DC-current in the DC-link. This paper is about the analytical calculation of the line side behaviour of an uncontrolled B12- rectifier with capacitive DC smoothing. The analytical calculation enables to quantify the effects on the line current in a very short time compared to time consuming simulation studies. This publication only deals with the DC- current that has no gaps. The piecewise determined currents on the secondary side of the transformer are transformed to the primary side. After that, the spectrum of the mains current can be determined easily. The experimental analysis in this paper will verify the analytical calculation.
\end{abstract}

\section{Key words}

Analytical calculation, uncontrolled B12 rectifier, capacitive DC- smoothing, verifying measurements

\section{Introduction}

Supply authorities restrict the injection of harmonics of rectifier loads. Therefore the designer must be able to quantify the effect on the line current of different values of line reactances to obtain a practical concept. Twelvepulse rectifiers with ac- side reactance and capacitive load are frequently used to generate dc power, e.g. for the supply of voltage source inverter fed ac drives. Figure 1 shows the basic circuit of a 12- pulse diode rectifier with ideal DC-link voltage and the rectifier- transformer. In a 12- pulse diode rectifier it is assumed, that the DC-link voltage is ideal because of the high number of pulses. For the analytical calculation of the net current it is assumed, that

- Diodes are ideal

- Capacitance in the DC- link is infinite
- Public power supply is symmetrical and free of impedance

- Impedances of the transformer are linear and have no losses

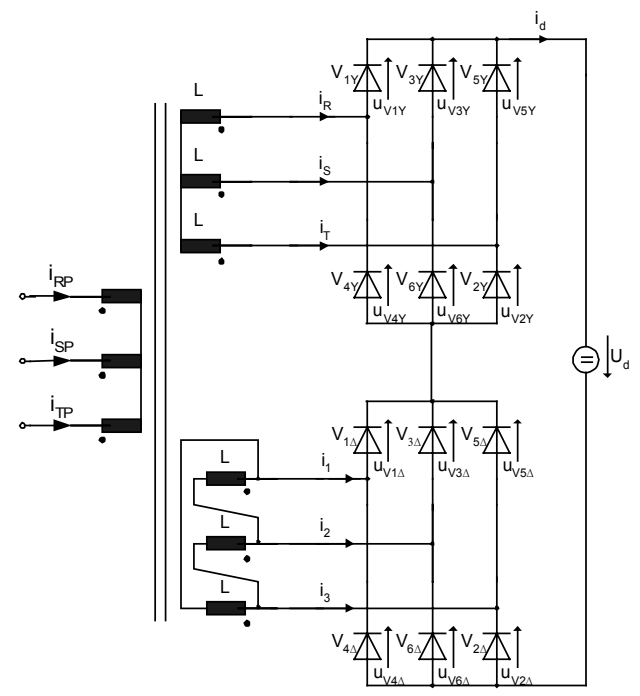

Figure 1: Basic circuit of a 12-pulse diode rectifier with ideal DC-link voltage and the rectifier transformer.

\section{Modelling for calculation}

Due to the series connection of two B6- diode bridges, 4 diodes always conduct the current. The secondary phase currents of the two transformers are the same apart from a phase shift of only $30^{\circ} \mathrm{el}$. For an easier calculation of the net current, the delta connected circuit in figure 1 is converted into an equivalent star connected circuit. 


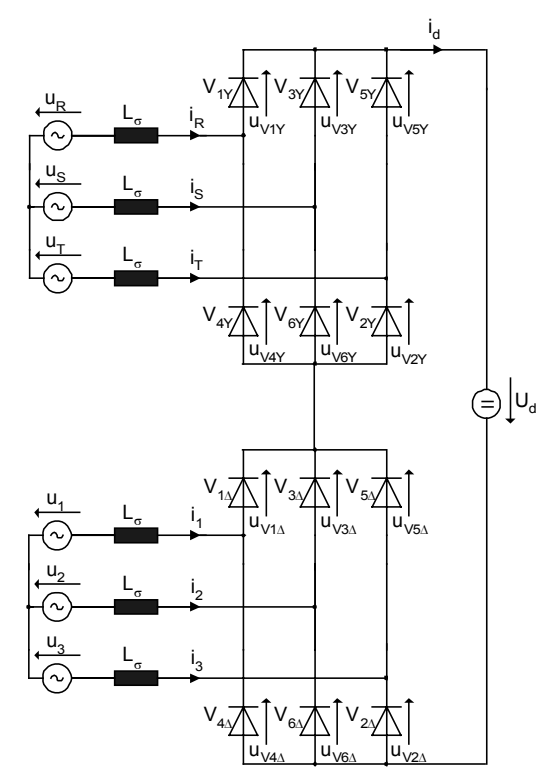

Figure 2: Equivalent circuit of the 12- pulse rectifier for the analytival calculation of the net current.

On the assumption that the primary stray reactance can be neglected, there is a cyclic and symmetric operation of the diode bridge and the rectifier is fully determined with only the twelfth of one period. Therefore the following analysis is restricted to two sequenced start-up times. For the calculation, the current in phase $\mathrm{R}$ of the $\mathrm{B} 6$ diode bridge (figure 2) is chosen. Table 1 shows which diodes conduct during the positive alternation in phase R. Some characteristic time behaviours are shown in figure 3 to explain the basic definitions for calculation.

Table 1: Conducting valves during the positive alternation in phase R.

\begin{tabular}{|c|c|}
\hline period of time & conducting valves \\
\hline $0 \leq \omega t \leq u$ & $\mathrm{~V}_{1 \mathrm{Y}}, \mathrm{V}_{5 \mathrm{Y}}, \mathrm{V}_{6 \mathrm{Y}}, \mathrm{V}_{5 \Delta}, \mathrm{V}_{6 \Delta}$ \\
\hline$u \leq \omega t \leq \pi / 6$ & $\mathrm{~V}_{1 \mathrm{Y}}, \mathrm{V}_{6 \mathrm{Y}}, \mathrm{V}_{5 \Delta}, \mathrm{V}_{6 \Delta}$ \\
\hline$\pi / 6 \leq \omega t \leq \pi / 6+u$ & $\mathrm{~V}_{1 \mathrm{Y}}, \mathrm{V}_{6 \mathrm{Y}}, \mathrm{V}_{1 \Delta}, \mathrm{V}_{5 \Delta}, \mathrm{V}_{6 \Delta}$ \\
\hline$\pi / 6+u \leq \omega t \leq \pi / 3$ & $\mathrm{~V}_{1 \mathrm{Y}}, \mathrm{V}_{6 \mathrm{Y}}, \mathrm{V}_{1 \Delta}, \mathrm{V}_{6 \Delta}$ \\
\hline$\pi / 3 \leq \omega t \leq \pi / 3+u$ & $\mathrm{~V}_{1 \mathrm{Y}}, \mathrm{V}_{2 \mathrm{Y}}, \mathrm{V}_{6 \mathrm{Y}}, \mathrm{V}_{1 \Delta}, \mathrm{V}_{6 \Delta}$ \\
\hline$\pi / 3+u \leq \omega t \leq \pi / 2$ & $\mathrm{~V}_{1 \mathrm{Y}}, \mathrm{V}_{2 \mathrm{Y}}, \mathrm{V}_{1 \Delta}, \mathrm{V}_{6 \Delta}$ \\
\hline$\pi / 2 \leq \omega t \leq \pi / 2+u$ & $\mathrm{~V}_{1 \mathrm{Y}}, \mathrm{V}_{2 \mathrm{Y}}, \mathrm{V}_{1 \Delta}, \mathrm{V}_{2 \Delta}, \mathrm{V}_{6 \Delta}$ \\
\hline$\pi / 2+u \leq \omega t \leq 2 \cdot \pi / 3$ & $\mathrm{~V}_{1 \mathrm{Y}}, \mathrm{V}_{2 \mathrm{Y}}, \mathrm{V}_{1 \Delta}, \mathrm{V}_{2 \Delta}$ \\
\hline $2 \cdot \pi / 3 \leq \omega t \leq 2 \cdot \pi / 3+u$ & $\mathrm{~V}_{1 \mathrm{Y}}, \mathrm{V}_{2 \mathrm{Y}}, \mathrm{V}_{3 \mathrm{Y}}, \mathrm{V}_{1 \Delta}, \mathrm{V}_{2 \Delta}$ \\
\hline $2 \cdot \pi / 3+u \leq \omega t \leq \pi$ & $\mathrm{V}_{2 \mathrm{Y}}, \mathrm{V}_{3 \mathrm{Y}}, \mathrm{V}_{1 \Delta}, \mathrm{V}_{2 \Delta}$ \\
\hline
\end{tabular}

The angle $\alpha$ describes the angle between the zero crossing of the voltage $u_{R}$ with positive slope and the beginning of conducting of valve $\mathrm{V}_{1 \mathrm{Y}}$ at $\omega \mathrm{t}=0$ respectively the zero crossing of the voltage $u_{R}$ with negative slope and the beginning of conducting of valve $\mathrm{V}_{4 \mathrm{Y}}$. In normal use, the DC current flows continuous and the AC- current has gaps.

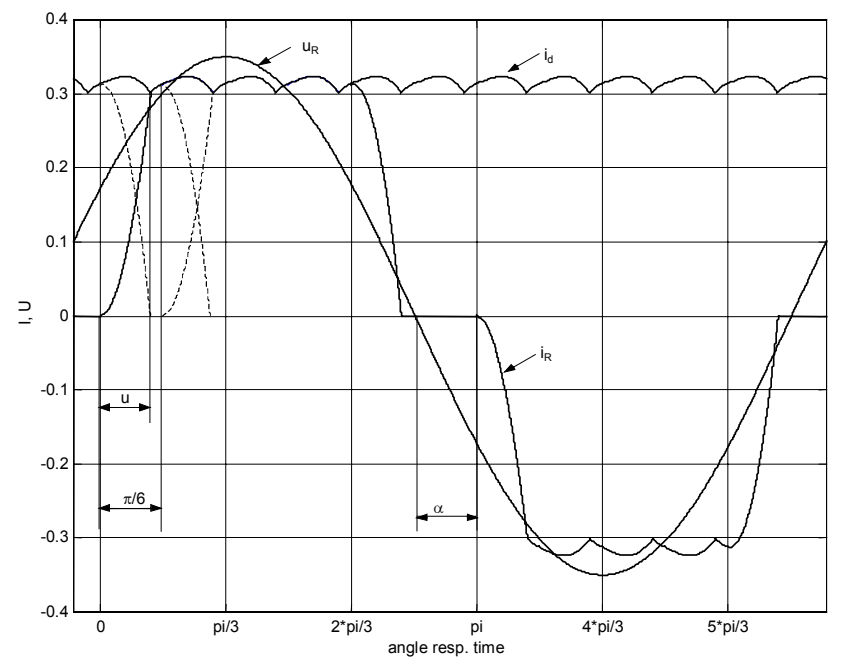

Figure 3: Definitions for calculation by characteristic time behaviours

Within this operation area, alternating 4 valves (outside the commutation) and 5 valves (during commutation) conduct. This operation area is limited by the voltage levels in the DC link. If the voltage level in the DC link is high only 4 diodes conduct. Respectively, with a low voltage level 5 diodes always conduct. These constraints give the main operating area of the 12 pulse bridge rectifier.

\section{Calculation of the time behaviour of the mains current}

\section{A. Difference equation of the DC current}

The difference equation of the DC- current makes it possible to calculate the DC- current $i_{d}$ at the beginning of each commutation. This difference equation yields to the constraint to solve the differential equations of the system. At time $\mathrm{t}=0$ the current starts flowing in diode $\mathrm{V}_{1 \mathrm{Y}}$. The current $i_{\mathrm{R}}$ at this juncture is $0\left(\mathrm{i}_{\mathrm{R}}(0)=0\right)$. The voltage sources in figure 2 have the following time behaviours:

$$
\begin{aligned}
& u_{R}=\hat{u} \cdot \sin (\omega t+\alpha) \\
& u_{S}=\hat{u} \cdot \sin (\omega t+\alpha-2 \pi / 3) \\
& u_{T}=\hat{u} \cdot \sin (\omega t+\alpha+2 \pi / 3) \\
& u_{1}=\hat{u} \cdot \sin (\omega t+\alpha-\pi / 6) \\
& u_{2}=\hat{u} \cdot \sin (\omega t+\alpha-5 \pi / 6) \\
& u_{3}=\hat{u} \cdot \sin (\omega t+\alpha+3 \pi / 6) \\
& U_{d}=\text { const. }
\end{aligned}
$$

As it can be seen from figure 3 , the diode bridge has in the period of time $0 \leq t \leq u / \omega$ the states shown in figure 4. The differential equation of the system, that is valid at this period of time, is:

RE\&PQJ, Vol. 1, No.2, April 2004 


$$
\begin{aligned}
& L_{\sigma} \cdot \frac{d i_{R}}{d t}+3 \cdot L_{\sigma} \cdot \frac{d i_{d}}{d t}=\sqrt{3} \cdot \hat{u} \\
& \cdot\left[\cos \left(\omega t+\alpha-\frac{\pi}{3}\right)+\cos \left(\omega t+\alpha-\frac{\pi}{6}\right)\right]-U_{d}
\end{aligned}
$$

The trigonometric terms on the right side of the equation (2) are given with an addition theorem that is used for the voltages $\mathrm{u}_{\mathrm{RS}}=\mathrm{u}_{\mathrm{R}}-\mathrm{u}_{\mathrm{S}}$ and $\mathrm{u}_{23}=\mathrm{u}_{2}-\mathrm{u}_{3}$.

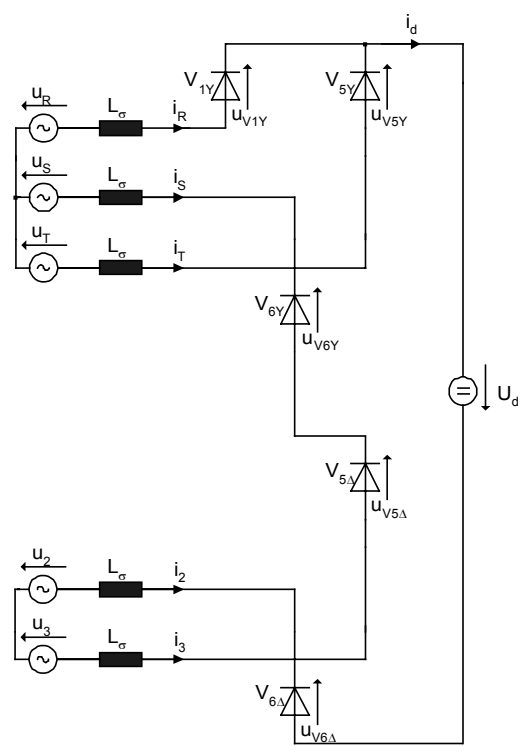

Figure 4: B12- diodebridge during commutation from diode $\mathrm{V}_{5 \mathrm{Y}}$ to diode $\mathrm{V}_{1 \mathrm{Y}}$.

The next step is the calculation of the current time behaviour after commutation from valve $\mathrm{V}_{5 \mathrm{Y}}$ to valve $\mathrm{V}_{1 \mathrm{Y}}(u / \omega \leq t \leq(\pi / 6) / \omega)$. The states of the diode bridge during this period of time are shown in figure 5 . The differential equation of the system that is valid at this period of time is:

$$
\begin{aligned}
& 4 \cdot L_{\sigma} \cdot \frac{d i_{d}}{d t}=\sqrt{3} \cdot \hat{u} . \\
& {\left[\cos \left(\omega t+\alpha-\frac{\pi}{3}\right)+\cos \left(\omega t+\alpha-\frac{\pi}{6}\right)\right]-U_{d}}
\end{aligned}
$$

The trigonometric terms on the right side of the equation (3) are given with an addition theorem that is used for the voltages $\mathrm{u}_{\mathrm{RS}}=\mathrm{u}_{\mathrm{R}}-\mathrm{u}_{\mathrm{S}}$ and $\mathrm{u}_{23}=\mathrm{u}_{2}-\mathrm{u}_{3}$. With these two equations $((2),(3))$ the two possible operating conditions of the diode bridge are known. The first order differential equations are solved by simple integration within their valid operating areas.

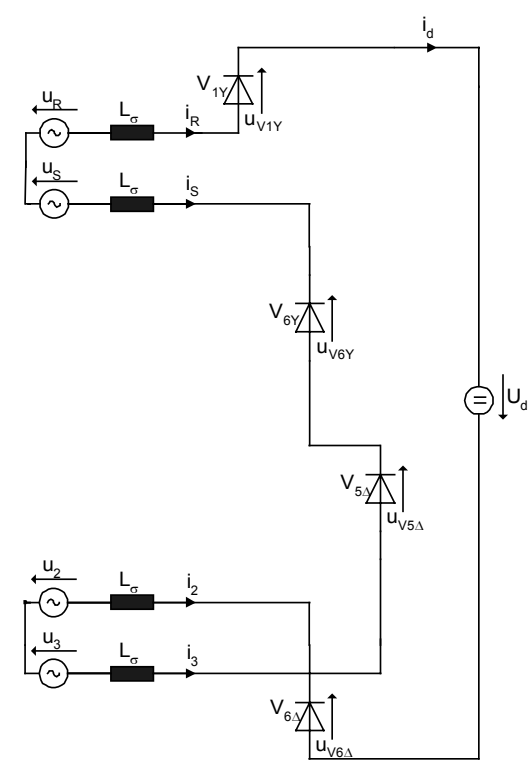

Figure 5: B12- diodebridge after commutation from diode $\mathrm{V}_{5 \mathrm{Y}}$ to diode $\mathrm{V}_{1 \mathrm{Y}}$.

Integrating equation (2) and consideration of the boundary conditions for $\mathrm{i}_{R}(0)=0$ and $\mathrm{i}_{\mathrm{R}}(\mathrm{u})=\mathrm{i}_{\mathrm{d}}(\mathrm{u})$ yields to:

$$
\begin{aligned}
& L_{\sigma} \cdot\left[4 \cdot i_{d}(u / \omega)-3 \cdot i_{d}(0)\right] \\
& =\frac{\sqrt{3} \cdot \hat{u}}{\omega} \cdot\left[\sin \left(u+\alpha-\frac{\pi}{3}\right)+\sin \left(u+\alpha-\frac{\pi}{6}\right)\right. \\
& \left.\quad-\sin \left(\alpha-\frac{\pi}{3}\right)-\sin \left(\alpha-\frac{\pi}{6}\right)\right]-U_{d} \cdot \frac{u}{\omega}
\end{aligned}
$$

After integration, equation (3) yields to:

$$
\begin{aligned}
& 4 \cdot L_{\sigma} \cdot\left[i_{d}((\pi / 6) / \omega)-i_{d}(u / \omega)\right] \\
& =\frac{\sqrt{3} \cdot \hat{u}}{\omega} \cdot\left[\sin \left(\alpha-\frac{\pi}{6}\right)+\sin (\alpha)\right. \\
& \left.-\sin \left(u+\alpha-\frac{\pi}{3}\right)-\sin \left(u+\alpha-\frac{\pi}{6}\right)\right]-U_{d} \cdot \frac{\pi / 6-u}{\omega}
\end{aligned}
$$

Equation (4) and equation (5) are independent and there are 5 unknown variables $\left(\mathrm{u}, \mathrm{i}_{\mathrm{d}}(\pi / 6), \mathrm{i}_{\mathrm{d}}(0), \mathrm{i}_{\mathrm{d}}(\mathrm{u}), \alpha\right)$. Adding these two equations, terms that are containing the overlap angel $\mathrm{u}$ are eliminated. Adding these two equations yields to the "difference equation of the DC- current" with 3 more unknown variables $\left(i_{d}(\pi / 6), i_{d}(0), \alpha\right)$ :

$$
\begin{aligned}
& i_{d}((\pi / 6) / \omega)-\frac{3}{4} \cdot i_{d}(0)= \\
& =\frac{\sqrt{3} \cdot \hat{u}}{4 \cdot \omega \cdot L_{\sigma}} \cdot \cos \left(\alpha-\frac{\pi}{6}\right)-\frac{U_{d}}{4 \cdot L_{\sigma}} \cdot \frac{\pi / 6}{\omega}
\end{aligned}
$$

Considering symmetrical conditions at steady state operation the DC currents at $\pi / 6$ and 0 are equal $\left(\mathrm{i}_{\mathrm{d}}(\pi / 6)=\mathrm{i}_{\mathrm{d}}(0)\right)$. Now it is possible to calculate the DC current at the beginning of each commutation. 


$$
I_{d 0}=\frac{\sqrt{3} \cdot \hat{u}}{\omega \cdot L_{\sigma}} \cdot \cos \left(\alpha-\frac{\pi}{6}\right)-\frac{U_{d}}{L_{\sigma}} \cdot \frac{\pi / 6}{\omega}
$$

The start up angle $\alpha$ is still unknown.

\section{B. Start up angle $\alpha$}

The three voltages of the transformer with delta connected windings are lagging behind $\left(30^{\circ} \mathrm{el}\right)$ the voltages of the transformer with star connected windings (with reference to the orientations and definitions in figure 1 and equation (1)). The B12 diode rectifierbridge consists of two series connected B6 diode bridges. The $\mathrm{B} 6$ diode bridge that is connected to the transformer with delta connected windings has the same current time behaviour as the $\mathrm{B} 6$ diode bridge that is connected to the transformer with star connected windings- only $30^{\circ} \mathrm{el}$ later. This fact causes the voltage over the diode $\mathrm{V}_{\Delta 1}$ to be zero at $\pi / 6$. The currents in the secondary transformer windings correspond to the DC current $i_{d}$. The voltage at valve $V_{\Delta 1}$ with respect to figure 6 is:

$$
u_{V \Delta 1}=-3 \cdot L_{\sigma} \cdot \frac{d i_{d}}{d t}+u_{R S}-U_{d}+u_{12}
$$

Inserting the definitions from equation (1) yields to:

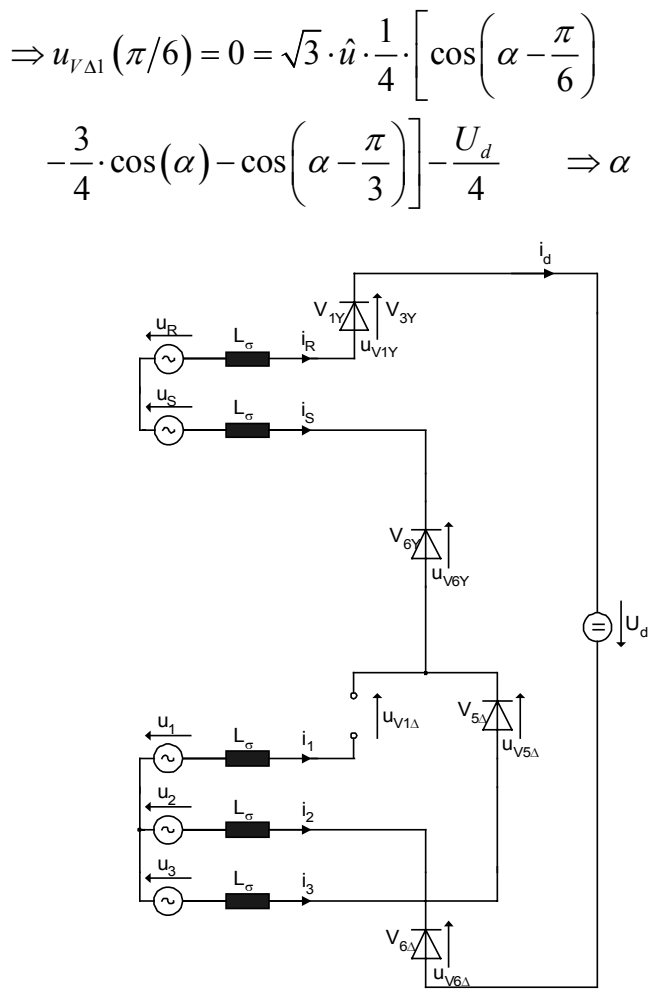

Figure 6: B12 diode bridge for calculation of voltage at valve

$$
\mathrm{V}_{\Delta 1} \text {. }
$$

As all boundary conditions are known, the currents can be calculated inserting the angle $\alpha$.

\section{Calculation of current time behaviour}

\section{1) Time behaviour during commutation}

Figure 4 shows the conditions in the B12 diode bridge that are valid during this period of time. With respect to Kirchhoff I, currents $-i_{2}, i_{3},-i_{S}$ and $i_{d}$ are equal during this period of time. This leads to the differential equations for the currents:

$$
\begin{aligned}
\frac{d i_{R}}{d t} & =\frac{1}{7 \cdot L_{\sigma}} \cdot\left(-3 \cdot u_{T R}+u_{R S}-u_{23}-U_{d}\right) \\
\frac{d i_{T}}{d t} & =\frac{1}{7 \cdot L_{\sigma}} \cdot\left(3 \cdot u_{T R}+u_{T S}-u_{23}-U_{d}\right) \\
\frac{d i_{d}}{d t} & =\frac{1}{7 \cdot L_{\sigma}} \cdot\left(u_{R S}+u_{T S}-2 \cdot u_{23}-2 \cdot U_{d}\right)
\end{aligned}
$$

Equation (10) shows $i_{R}$ which describes the commutating current that starts to flow, $\mathrm{i}_{\mathrm{T}}$ gives the current during commutation that goes to zero and $i_{d}$ gives the current in the DC- link. Current $\mathrm{i}_{\mathrm{T}}$ makes it possible to calculate the overlap angle $\mathrm{u}$ with the following transcendent equation which is solved iterative:

$$
\begin{aligned}
& i_{T}(u / \omega)=0=\frac{\sqrt{3} \cdot \hat{u}}{7 \cdot \omega \cdot L_{\sigma}} \cdot\left[3 \cdot \sin \left(u+\alpha+\frac{\pi}{3}\right)\right. \\
& -3 \cdot \sin \left(\alpha+\frac{\pi}{3}\right)+\sin \left(u+\alpha-\frac{\pi}{3}\right)-\sin (\alpha) \\
& +\sin \left(u+\alpha-\frac{\pi}{6}\right)+\sin \left(\alpha-\frac{\pi}{6}\right) \\
& \left.+7 \cdot \cos \left(\alpha-\frac{\pi}{6}\right)\right]-\frac{U_{d}}{L_{\sigma}} \cdot\left(\frac{u}{7 \cdot \omega}+\frac{\pi / 6}{\omega}\right)
\end{aligned}
$$

\section{2) Time behaviour after commutation}

During this time period the time behaviour of the current is given with the differential equation (3). This equation is calculated with respect to figure 5 .

With these equations, all interesting current time behaviours are known. To calculate a whole period of the secondary transformer current, it is possible to shift the time base of the currents already calculated.

\section{Definition of operation area}

\section{1) Lower bound of operation area}

The value of the DC link voltage gives the boundaries of the operation area. If the DC link voltage is low, 5 valves will conduct enduringly.

At higher level of the DC- link voltage 4 or 5 diodes conduct alternately. The border of these two operation areas is given if the overlap angle $u$ is similar to $\pi / 6$. To get this border, the current that goes to zero during commutation is taken $\left(\mathrm{i}_{\mathrm{T}}\right)$. For this purpose, equation (11) makes it possible to calculate the value of the DC link voltage where the overlap angle $u=\pi / 6$. The solution is found iteratively: 


$$
U_{d}=3.1032 \cdot \hat{u}_{\text {star-connected }}
$$

\section{2) Upper bound of operation area}

If the voltage level in the DC link rises (eg.: at no or low load conditions) there will be a gap in the DC current $i_{d}$.

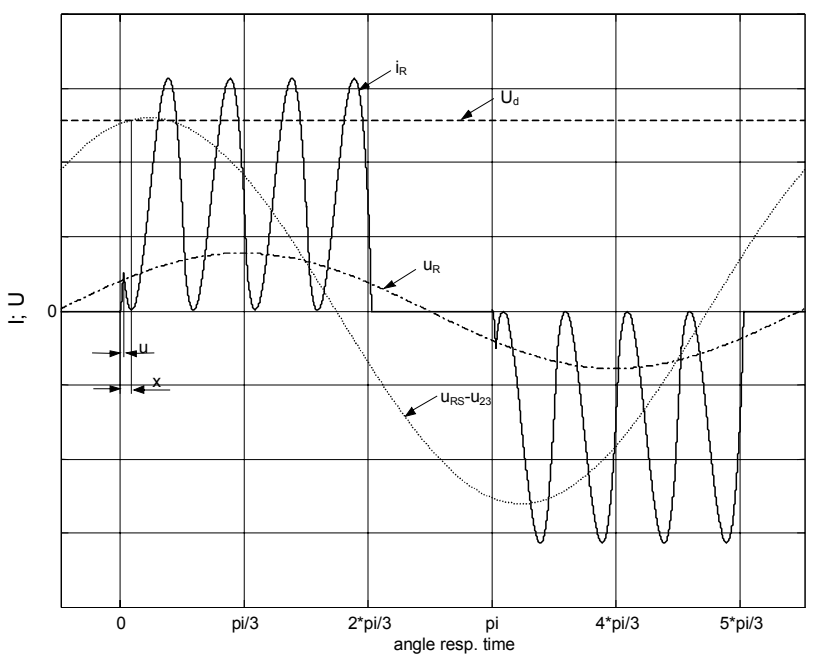

Figure 7: Current time behaviour in phase $\mathrm{R}$ at upper bound of operation (qualitative).

Figure 7 shows that at time $t=0$ the current in phase $R$ starts flowing. The small notch represents the end of commutation (u). After this, the diode bridge has the circuit diagram shown in figure 5. At that high level of the DC- link voltage, the current reaches zero again (x). If the driving voltage $\left(\mathrm{u}_{\mathrm{RS}}-\mathrm{u}_{23}\right)$ level is higher than the voltage level in the DC link, the current starts flowing again. At the gap- border the voltage in the DC link is similar to the driving voltage $\left(\mathrm{U}_{\mathrm{d}}=\mathrm{u}_{\mathrm{RS}}-\mathrm{U}_{23}\right)$. This condition yields to an explicit expression for $\mathrm{x}$ :

$$
\begin{aligned}
& U_{d}=\hat{u} \cdot \sqrt{3} \cdot\left[\cos \left(x+\alpha-\frac{\pi}{3}\right)+\cos \left(x+\alpha-\frac{\pi}{6}\right)\right] \\
& \Rightarrow x=a \sin \left(\frac{U_{d}}{2 \cdot \sqrt{3} \cdot \hat{u} \cdot \cos (-\pi / 12)}\right)-\alpha-\frac{\pi}{4}
\end{aligned}
$$

The solution of equation (3) results in the time behaviour of the current in phase R after commutation. This current is zero at the gap-border at position $\mathrm{x}$.

$$
\begin{gathered}
i_{R}(x)=0=\frac{\sqrt{3} \cdot \hat{u}}{4 \cdot \omega \cdot L_{\sigma}} \cdot\left[\sin \left(x+\alpha-\frac{\pi}{3}\right)\right. \\
+\sin \left(x+\alpha-\frac{\pi}{6}\right)-\sin \left(\alpha-\frac{\pi}{6}\right) \\
\left.-\sin (\alpha)+4 \cdot \cos \left(\alpha-\frac{\pi}{6}\right)\right] \\
-\frac{U_{d}}{4 \cdot L_{\sigma}} \cdot\left(\frac{x}{\omega}+\frac{3 \cdot \pi / 6}{\omega}\right)
\end{gathered}
$$

Equation (13) is inserted at position $\mathrm{x}$ in equation (14). With this solution it is possible to calculate the upper bound of the operation area iteratively. The upper bound of the DC link voltage level results in:

$$
U_{d}=3,3060 \cdot \hat{u}_{\text {star-connected }}
$$

\section{E. Time behaviour of primary transformer current}

The calculations under point $\mathrm{C}$ give only a description of the time behaviour of the current at the secondary side of the transformer. The current in phase $\mathrm{R}$ is explicitly described in this paper. To get the current in phase 1, it is necessary to shift the time base of the currents temporally of $30^{\circ} \mathrm{el}$ (definitions in equation 1). But the current in phase 1 is not the same at the primary side of the transformer. This is because of the delta connected windings. The number of windings in the delta connected transformer has to be higher than in the transformer that is star connected. The factor is exact the square root of 3 . The current on the primary side of the transformer with delta connected windings is calculated in this way:

$$
i_{12}=\frac{1}{3} \cdot\left(i_{1}-i_{2}\right)
$$

Equation (16) enables to calculate the primary current of the delta connected transformer.

Figure 8 shows the time behaviour of the current in phase $\mathrm{R}$ (star connected transformer windings) and figure 9 shows the time behaviour of the current in phase 12 (delta connected transformer windings). The sum of these two currents yields to the time behaviour of the current on the primary side of the transformer (figure 10). The time behaviour of the current shown in figure 10 gives the resulting spectrum of the primary current with a simple fourier analysis (figure 11). Making use of a 12 pulse transformer has some advantages, one of which is, that the $5^{\text {th }}$ and $7^{\text {th }}$ harmonic are eliminated automatically. There are only harmonics with orders: $h=n \cdot p \pm 1$ with $\mathrm{n}=1,2,3, \ldots$ (p...number of pulses). The reason for that is the phase shift of the two secondary transformer voltages. The phase shift of the voltages leads to a phase displacement to the $5^{\text {th }}$ harmonic of $-180^{\circ} \mathrm{el}$ and a phase displacement of $+180^{\circ} \mathrm{el}$ to the $7^{\text {th }}$ harmonic. This leads to an elimination of these harmonics. 


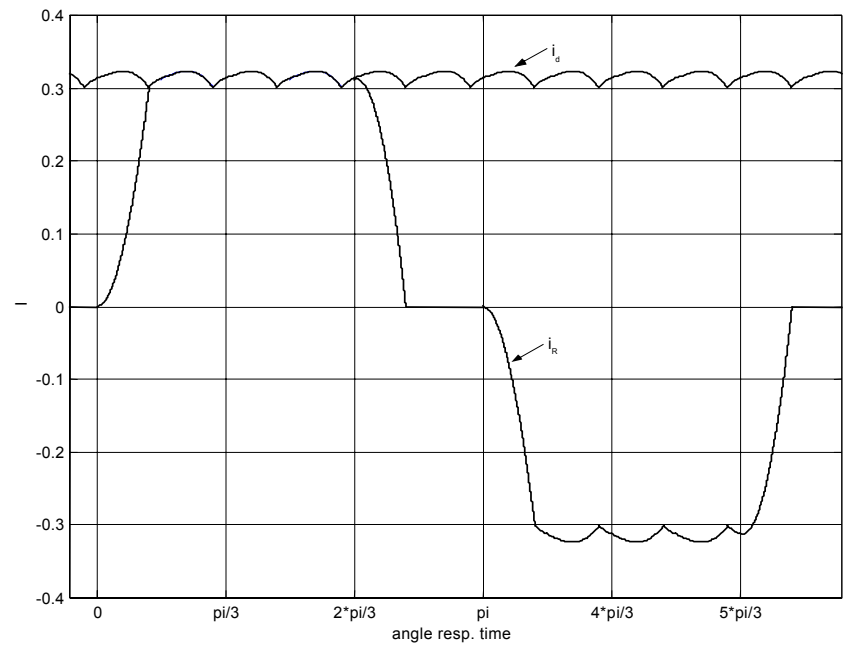

Figure 8: Qualitative time behaviour of the current in phase R.

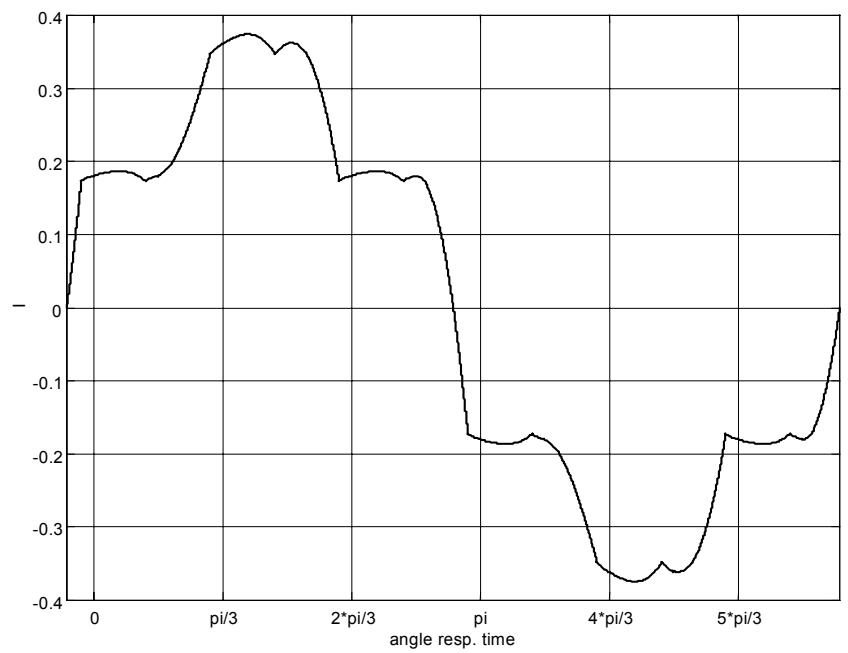

Figure 9: Qualitative time behaviour of the current in phase 12.

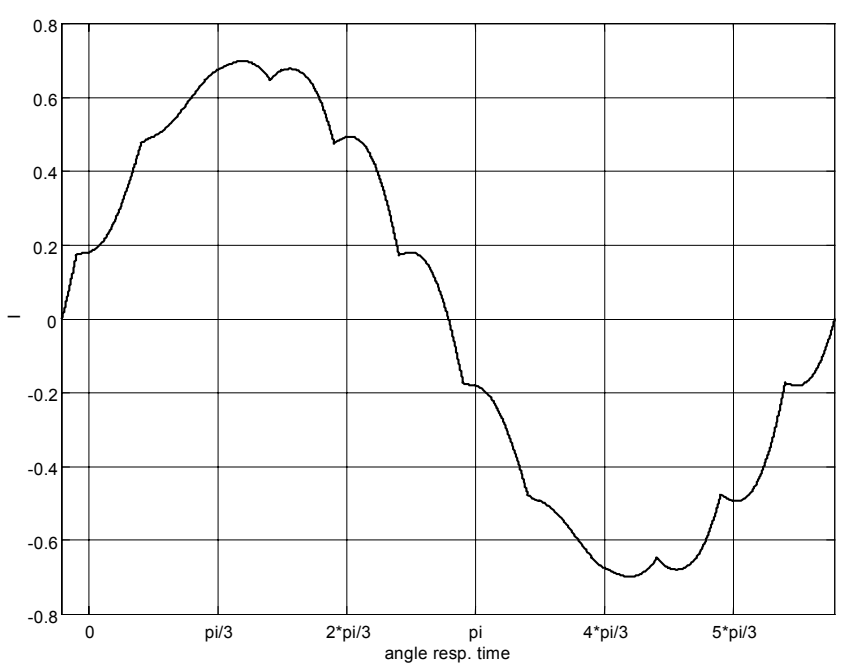

Figure 10: Qualitative time behaviour of the current on the primary side of the transformer during a whole period.
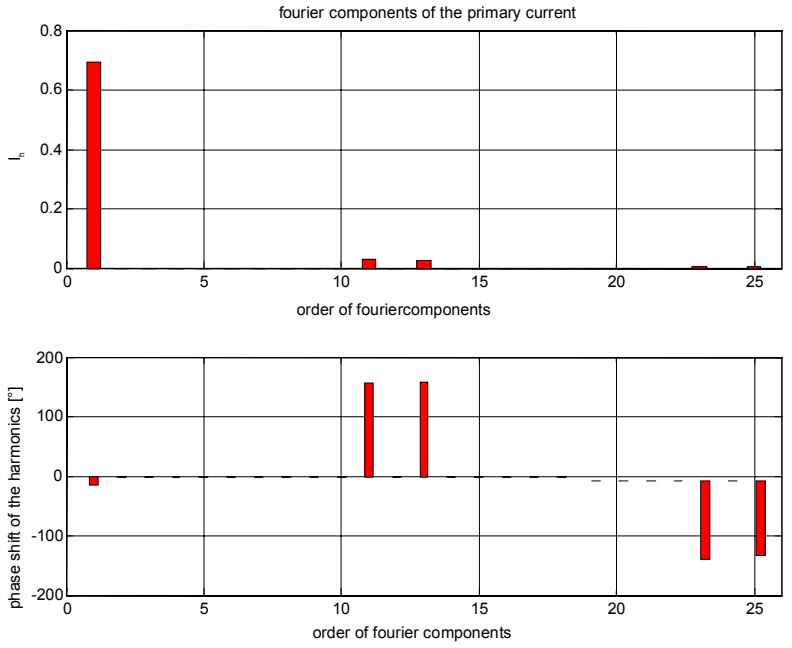

Figure 11: Magnitude and phase angle of the Fourier analysis of the current in figure 10.

\section{Experimental analysis}

The measurements were done with two transformers, where the first one is connected in star and the second one in delta. The power rating of each transformer is $10 \mathrm{kVA}$. The whole reactance (supply and transformer) $\mathrm{x}_{\mathrm{k}}$ is $36.6 \%$. The conductance $r_{k}$ is $7 \%$. The capacitance in the DC link is $2.2 \mathrm{mF}$. The following measurements show the mains current and spectrum with different power ratings on the $\mathrm{DC}$ side. The load is made with a simple resistor. The capacitance in the DC- link decouples the load and supply network.

\section{A. DC output power: $5.5 \mathrm{~kW}$}

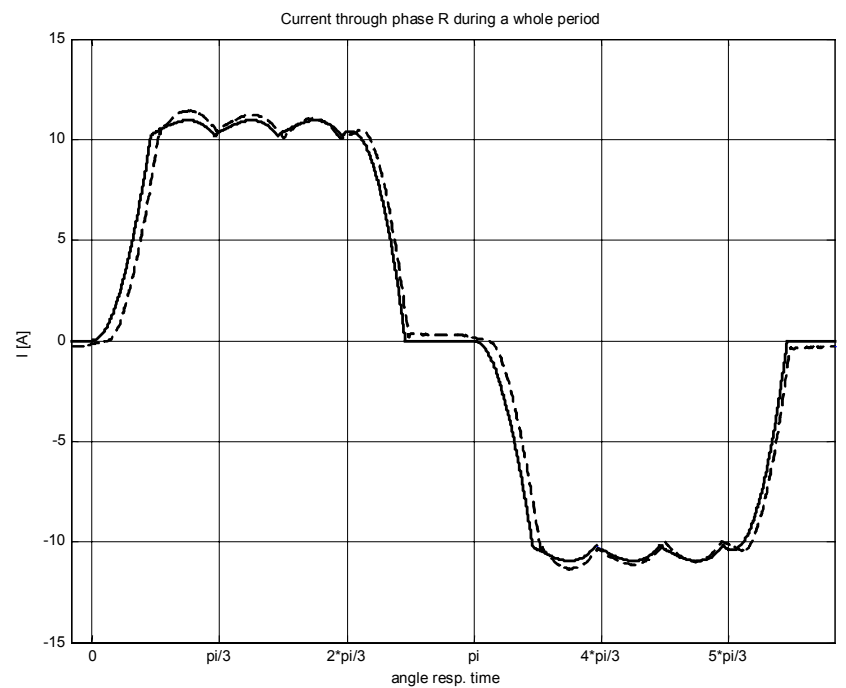

Figure12: Time behaviours of calculated (solid) and measured (dashed) current in phase R. 


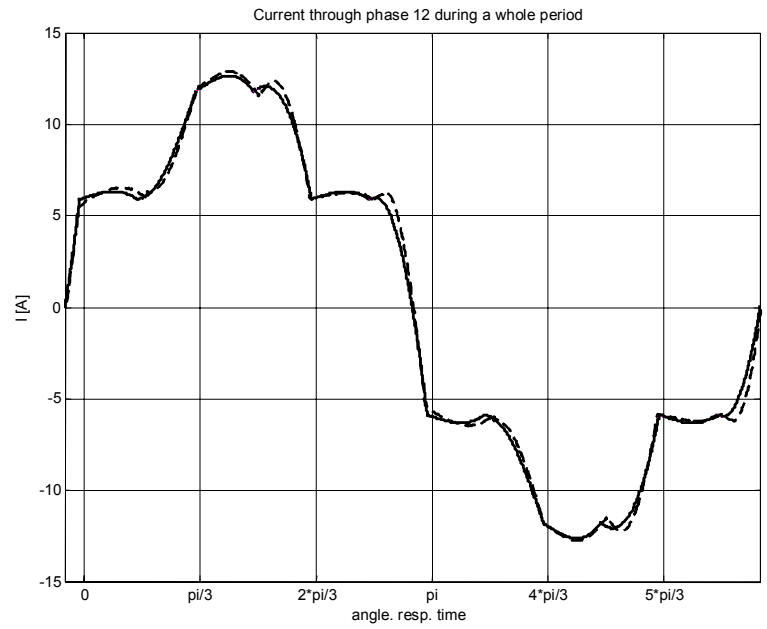

Figure 13: Time behaviours of calculated (solid) and measured (dashed) current in phase 12.

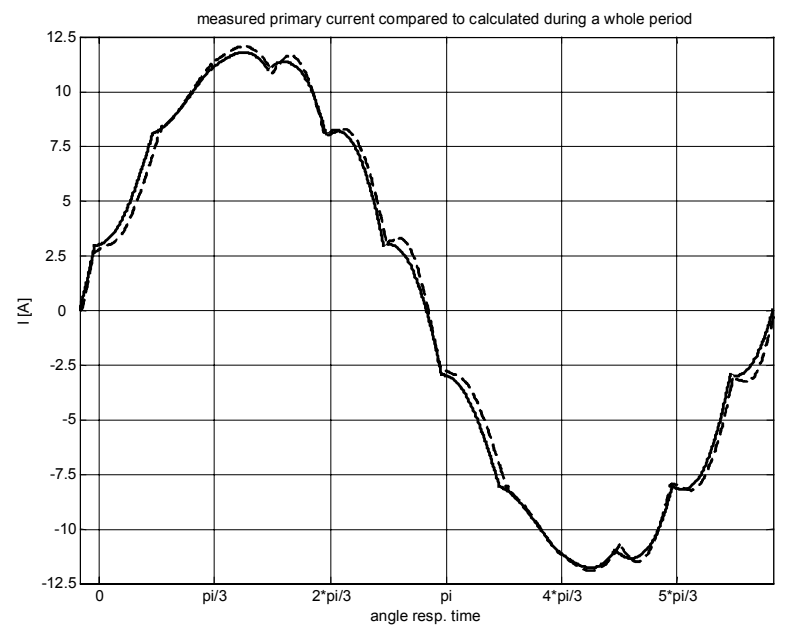

Figure 14: Time behaviours of calculated (solid) and measured (solid) current on the primary side of the transformer.

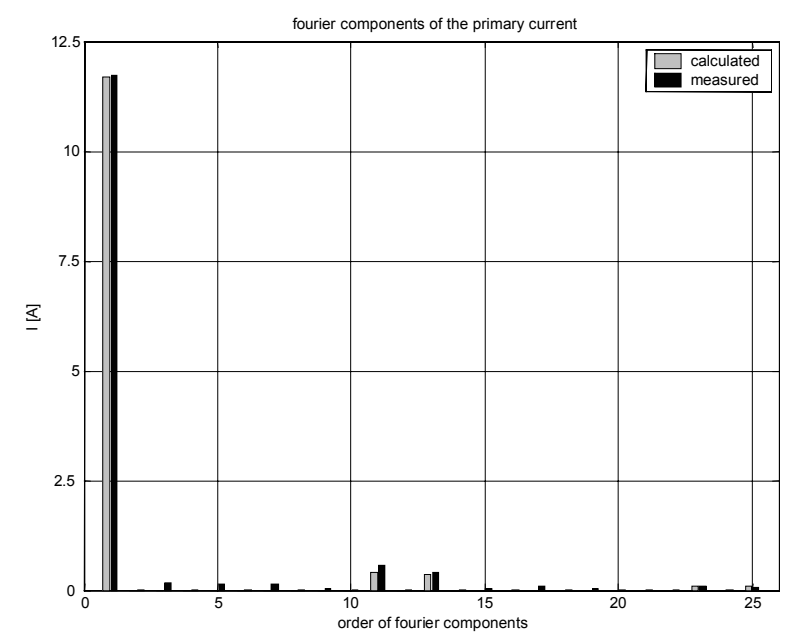

Figure 15: Fourier components of the current on the primary side of the transformer.
B. DC output power: $1.6 \mathrm{~kW}$

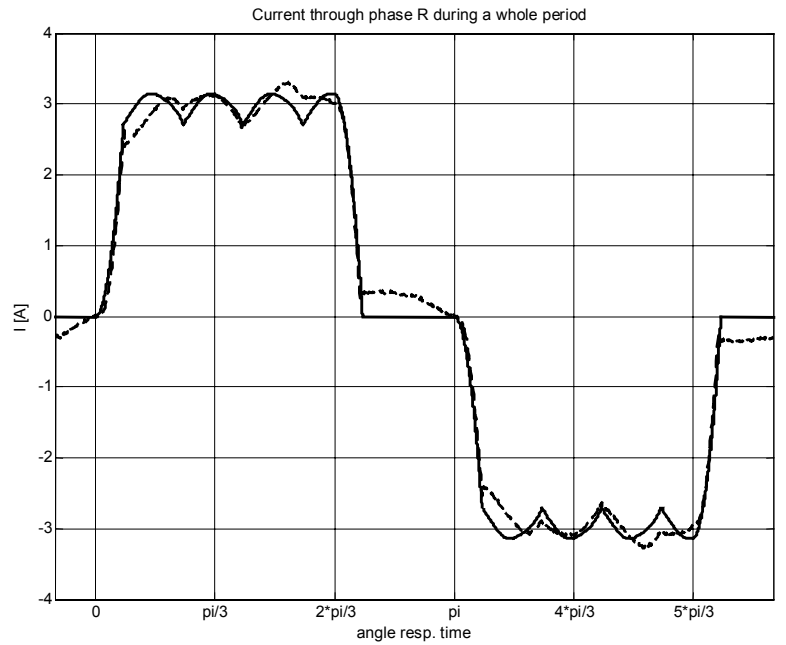

Figure 16: Time behaviours of calculated (solid) and measured (dashed) current in phase R.

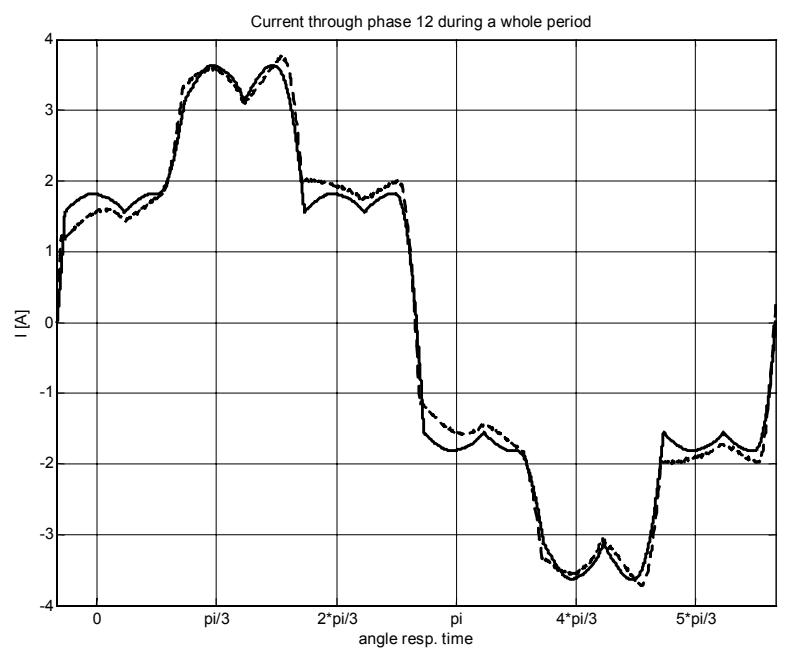

Figure 17: Time behaviours of calculated (solid) and measured (dashed) current in phase 12 .

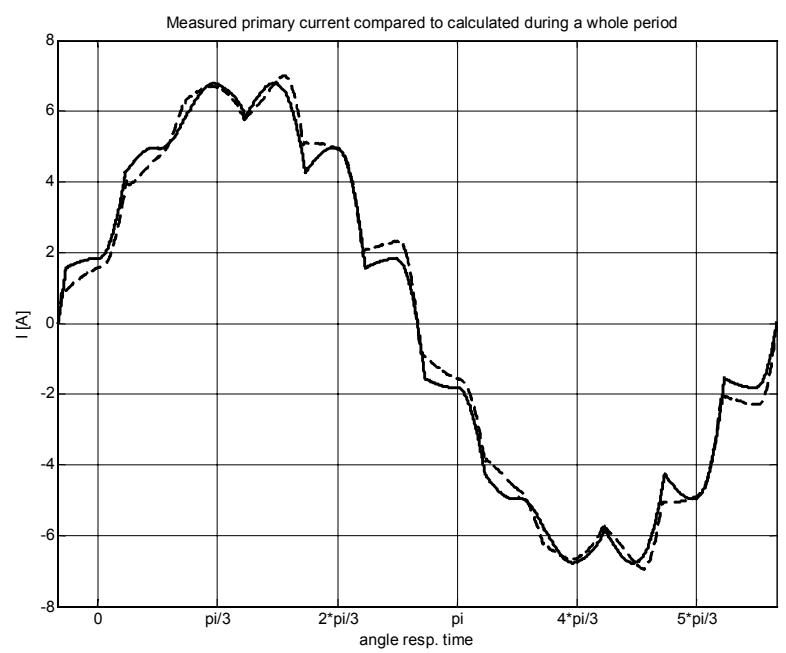

Figure 18: Time behaviours of calculated (solid) and measured (dashed) current on the primary side of the transformer. 


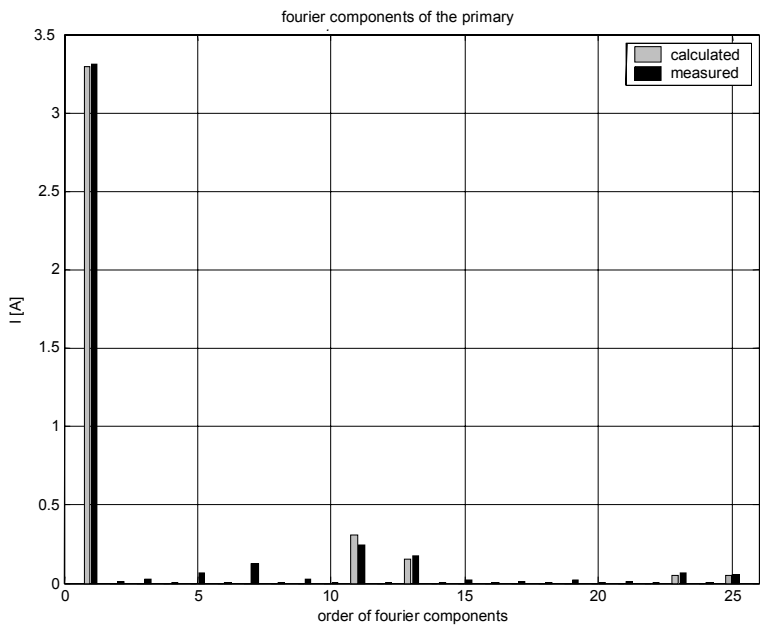

Figure 19: Fourier components of the current on the primary side of the transformer.

\section{Conclusion}

The difference equation of the DC current gives the chance to calculate the value of the DC current at the beginning of each commutation. This solution leads to the piecewise description of the current on the secondary side of the transformer. The ohmic resistances are neglected. The voltages are symmetric. The assumption of an ideal DC voltage in the DC link is allowable because of the high number of pulses (12). The operating point of the diode bridge is determined by the power rating on the DC side $\left(\mathrm{P}_{\mathrm{d}}=\mathrm{U}_{\mathrm{d}} * \mathrm{I}_{\mathrm{dm}}, \mathrm{I}_{\mathrm{dm}} \ldots\right.$ average DC current). With an iteration method that is based on the voltage level in the DC link, the operating point is determined. The currents on the DC side of the transformer are transformed to the primary side and a fourier analysis yields to the spectrum of the mains current. This method makes it possible to quantify the effects of uncontrolled 12-pulse rectifiers with capacitive DC smoothing in a very short time, compared to time consuming simulation studies. Measurements verify the proposed method, as it can be seen in the figures 12-19. The line voltage for measurements is not sinusoidal. It shows a $5^{\text {th }}$ harmonic of about $2 \%$ and a $7^{\text {th }}$ harmonic of about $0.9 \%$. Therefore, the analytical calculation of the line current is a good approximation, because for calculation it is assumed that the voltage source is symmetric and sinusoidal. The measurements also show that the calculation is a good approximation whether if the power on the DC side is high or low.

\section{References}

[1] Grötzbach, M.: Berechung der Oberschwingungen im Netzstrom von Drehstrombrückenschaltungen bei unvollkommener Glättung des Gleichstroms. Etz Archiv, Bd. 7 (1985), S.59- 62

[2] Rechberger, T.: Analytische Berechnung der Netzrückwirkungen von ungesteuerten Gleichrichtern mit kapazitiver Glättung der Zwischenkreisspannung. Diplomarbeit 2001, ABB- Industrie AG Schweiz (Turgi), ETH Zürich, TU Wien 